EDITORIAL

\title{
Innovations in microinsurance research
}

\author{
David Mark Dror ${ }^{1} \cdot$ Martin Eling $^{2}$
}

(c) The Geneva Association 2021

True to its tradition of publishing special issues on emerging insurance topics, The Geneva Papers on Risk and Insurance-Issues and Practice continues this year with the fourth special issue on microinsurance. The journal published special issues on microinsurance previously in 2014 (vol. 39), 2016 (vol. 41) and 2019 (vol. 44). In considering the focus of the special issues on this theme, the Editor-in-Chief and the Editorial Board allowed the Guest Editor(s) freedom of choice. They gracefully refrained from taking a position on whether microinsurance required a separate theoretical framing or whether it should be analysed using classical models (thus suggesting that this is another type of insurance). It is helpful to recall that the term microinsurance was first used in an article published in 1999 (Dror and Jacquier 1999). It is also useful to remind that most of the printed material (this issue included) offers empirical analysis. We scoped the volume of publications on this topic in Google Scholar since 2000 (see Fig. 1). The first decade saw a tenfold increase in the number of publications per year, from about 100 to close to 1000 . After that, we witness a continued but lesser growth (the highest number of microinsurance publications per year, 2300, was recorded in 2014). The ResearchGate weekly reports of browses-downloads-citations also suggest an ever-increasing and widespread use of published material. The Web of Science count of microinsurance publications shows two peaks, in 2016 and 2019. These were the years when this journal published special issues on microinsurance. This suggests how significant the contribution of the special issues was to scientific (peer-reviewed) publications on this topic.

The more comprehensive treatises on microinsurance were published as books. Also, we recall region-specific scoping studies that have been the source of statistics on enrollments. Over this time, most authors have moved on from the initial preoccupation with definitions. We have one article summarising the developments in this

\section{Retired. Geneva, Switzerland}

Martin Eling

martin.eling@unisg.ch

1 Retired, Geneva, Switzerland

2 Institute of Insurance Economics, University of St. Gallen, Girtannerstrasse 6, 9010 St. Gallen, Switzerland 


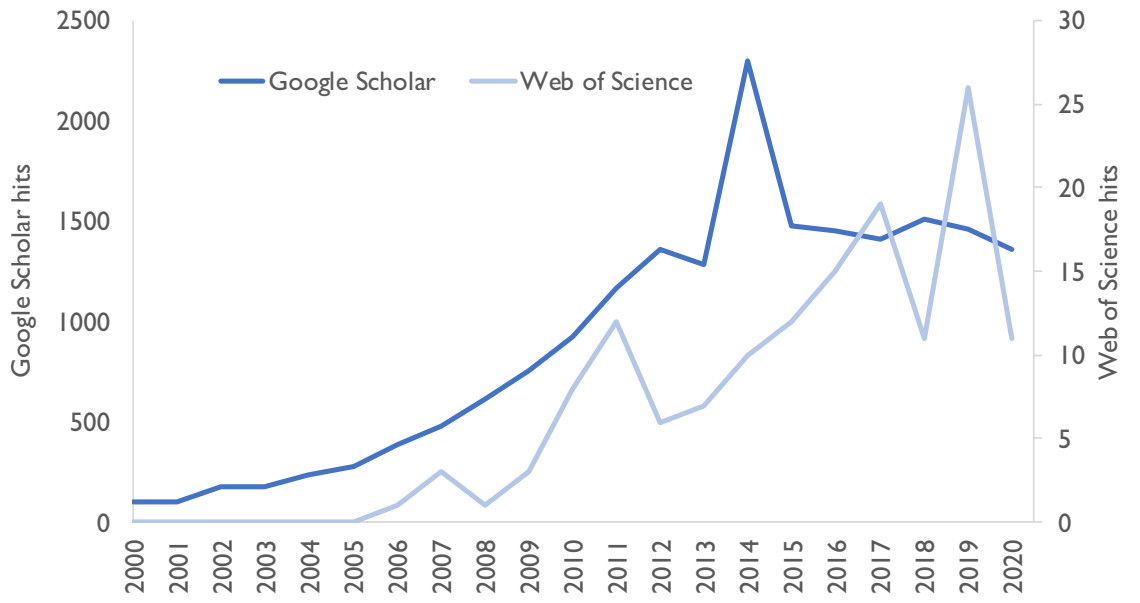

Fig. 1 Hits by year for search term microinsurance (as of 17 April 2021)

space over its 20 year history (Dror 2019). We now have several contributions to the theoretical framework and the theory of demand for microinsurance. Yet, most articles dealt with narrower (often unique) settings. The diversity of backgrounds emphasises why microinsurance is a complex topic. The many new methods demonstrate the colossal need for solutions to many of the basics (e.g. obtaining data, asymmetric information, potential correlations, 'public good' character of products, group vs. individual choice, short-term vs. long-term welfare gains, (unexpected) impact of regulation, return on investment, etc.)

Most publications on microinsurance have been in the form of articles. This is due in part to the limited length of journal articles. Importantly, practitioners of microinsurance have taken the lead in innovating and analysing their experience. Just as the large financial institutions shied away from pulling their weight in developing microfinance, the leading players in the insurance and reinsurance industry do not yet support the development of microinsurance. Academia is also insufficiently present at the 'last mile' where microinsurance happens. Therefore, The Geneva Papers serves the industry well by informing it about analytical thinking in the microinsurance space by publishing the special issues dedicated to the topic.

This year's special issue on microinsurance includes seven articles selected from 14 submissions. Two authors who needed more time to revise their papers withdrew their submissions. The acceptance rate has been somewhat higher than two years ago, thanks mainly to the high quality of submissions. The authors have used a wide range of methodologies: from empirical analysis based on surveys (Akomea-Frimpong et al. 2021) to aggregated data (Tiemtore 2021), panel data based on more extensive empirical or experimental research (Banerjee and Savitha 2021), as well as logit (Cai et al. 2021) or probit regressions (Alhassan and Magazi 2021). Also, we included conceptual frameworks (Yan and Faure 2021) and an intensity-based semi-parametric multivariate recurrent event model 
(Zhang et al. 2021). Our thanks go to the authors for that. Four of the seven articles deal with the Asian environment, and the other three focus on Africa. As for the risk categories, one article discusses microinsurance in general (life and nonlife), four papers focus on life/health, and two on agricultural risks. It is noteworthy and commendable that four of the seven articles analyse the demand side, and three focus on supply-side frictions.

The first paper in this issue by Isaac Akomea-Frimpong, Caleb Boadi and Roger Owusu-Boafo is entitled Determinants and challenges of supplying microlife insurance in Ghana. Using factor analysis with principal component analysis, the authors present a holistic analysis of the determinants and challenges of providing life microinsurance in Ghana. They identify 20 critical determinants, classified into four groups (affordable but profit-oriented products, active consideration of consumeroriented conditions, strong internal position and controls, favourable external factors) and 39 challenges divided into five major groups (insufficient premium income, asymmetric information, weak internal systems, increased industry-related challenges, unfavourable external factors). The authors conclude that the determinants for the supply of life microinsurance included a suitable price strategy, minimised product costs and (perception of) fair risk-sharing. These determinants are critical in product development, claims settlement and managing administrative costs. These results might be beneficial for practitioners working on implementing microinsurance schemes and for researchers analysing outcomes.

The second paper, entitled Microinsurance and household asset welfare in South Africa, by Abdul Latif Alhassan and Noluyolo Magazi consider the effect of microinsurance on household assets by measuring an asset accumulation index. The asset accumulation index is based on 12 categories of private household asset (e.g. motor car, computer, washing machine, refrigerator). The results show that, when measuring welfare gains through asset accumulation, microinsurance contributes to financial protection. These results offer compelling arguments in favour of promoting insurance inclusion among low-income households.

Subrato Banerjee and Basri Savitha authored the third paper, entitled Competition reduces profitability: the case of the Indian life microinsurance industry. The authors offer an original look at the market and firm-level concentration on return on equity (ROE). Using data on 14 Indian life microinsurance companies active over the decade 2009-2019, they empirically test structure-performance issues. The authors calculate Herfindahl-Hirschman concentration indexes (HHI) and use panel data techniques to find a positive effect of concentration and a negative impact of market share. They conclude that specialised insurers in India perform better than diversified insurers. This conclusion upholds the structure-conduct-performance hypothesis that a highly concentrated market provides a higher ROE for shareholders.

Qingyin Cai, Yulian Ding, Calum Tuvey and Yuehua Zhang wrote the fourth article, entitled The influence of past experience on farmers' preferences for hog insurance products. The authors present a choice experiment among hog farms in four townships in China to explore the influence of experience with hog insurance on farmers' willingness to pay (WTP) for and preferences of hog insurance. They find a lot of heterogeneity in insurance attribute preferences. Past insurance experience 
plays a vital role in the demand for hog insurance and WTP. The authors conclude that government involvement in insurance operations is consistently essential.

The fifth article, Examining the effects of agricultural income insurance on farmers in Burkina Faso, by Abel Tiemtore focuses on the effectiveness of income insurance as a tool to increase the financial resilience of farmers when faced with joint yield and price risks. The author applies an optimisation method to national and regional data on maize yields and prices in Burkina Faso from 1995 to 2015. His results show that income insurance generates significant risk reduction at lower costs than other programmes such as index insurance or warrantage. This is particularly pertinent when much focus is directed at implementing index insurance for crop or livestock risks.

Yu Yan and Michael Faure authored the sixth article, entitled Government interventions in microinsurance: evidence from China. Considering that microinsurance activities suffer from severe market failures, and government interventions are increasingly used to stimulate this market, they evaluate the effectiveness of four primary areas of Chinese government interventions in microinsurance (subsidisation, simplification, encouraging group policies, and distribution channels). Their results highlight that government interventions are only effective when subsidies support innovative market practices, when insurance policies are easy to understand, when distributors are suitably trained and when group policies can be renewed.

The seventh article on Dynamic information asymmetry in micro health insurance: implications for sustainability was authored by Xiaoqi Zhang, Yi Chen and Yi Yao. The authors deal with one of the most fundamental problems of insurance economics, namely information asymmetry (adverse selection and moral hazard). They propose an appropriate method (comprising a series of non-parametric tests to discover reasons that lead to dynamic claims patterns) and novel test statistics (dynamic claims data in a multivariate recurrent event model) to detect information asymmetry. They conclude that adverse selection exists for various disease types and that moral hazard is only significant for chronic diseases. Furthermore, there is a trend of adverse selection in pregnancy-related claims. The results show other practitioners a method and novel test statistics to detect information asymmetry using dynamic claims data in a multivariate recurrent event model framework. This helps microinsurance practitioners to better understand the reasons for dynamic claims patterns and points to remedial actions to improve the sustainability of these programmes.

In the past, we were approached by several potential contributors with questions about the topics that might be suitable for publication in the special issue on microinsurance. The guest editors are of the view that we wish to stimulate future research on microinsurance in addition to publishing interesting articles. We have therefore added a few pointers on the published papers. For example, many analyses are limited in scope in terms of geographic areas or products so there is need to generalise results to other countries and contexts. Beyond that, Alhassan and Magazi suggest using panel data and other impact methodologies (e.g. differences in differences) to test the resilience of households over time. In line with these ideas, Zhang et al. suggest considering time-dependent tests in identifying adverse selection and moral hazard in micro health insurance. We also 
draw attention to topics that were not yet covered. Examples are the potential of blockchain technology to scale microinsurance through digitalised product design, distribution and claims processing (see e.g. Kshetri 2017) and the effect of COVID-19 on developing microinsurance (see Microinsurance Network 2020).

Finally, David M. Dror acted as Guest Editor from the inception of the special issues on microinsurance to date. He has done so in this issue for the last time. He wishes to express his heartfelt thanks to the Editor-in-Chief of The Geneva Papers on Risk and Insurance-Issues and Practice for having accepted the proposal to launch the special issues on microinsurance in 2014. It has been a labour of love and a great privilege to encourage so many practitioners to share their data, their analysis and their original methods and solutions freely and widely with everyone. David also thanks Martin Eling for having accepted to take over as Guest Editor of future special issues on microinsurance. The microinsurance community will surely draw many benefits from this smooth and suitable continuation.

\section{References}

Alhassan, A.L., Magazi, N. 2020. Microinsurance and household asset welfare in South Africa. Geneva Papers on Risk and Insurance: Issues and Practice. https://doi.org/10.1057/ s41288-020-00199-y

Akomea-Frimpong, I., Boadi, C., and Owusu-Boafo, R. 2021. Determinants and challenges of supplying microlife insurance in Ghana. Geneva Papers on Risk and Insurance: Issues and Practice. https:// doi.org/10.1057/s41288-021-00226-6.

Banerjee, S., and Savitha, B. 2021. Competition reduces profitability: the case of the Indian life microinsurance industry. Geneva Papers on Risk and Insurance: Issues and Practice. https://doi.org/10. 1057/s41288-020-00203-5

Cai, Q., Ding, Y., Tuvey, C., et al. 2021. The influence of past experience on farmers' preferences for hog insurance products: a natural experiment and choice experiment in China. Geneva Papers on Risk and Insurance: Issues and Practice. https://doi.org/10.1057/s41288-021-00209-7

Dror, D.M. 2019. Microinsurance-A short history. International Social Security Review 72 (4): 107126. https://doi.org/10.1111/issr.12223.

Dror, D.M., and C. Jacquier. 1999. Micro-insurance: Extending health insurance to the excluded. International Social Security Review 52 (1): 71-97.

Kshetri, N. 2017. Will blockchain emerge as a tool to break the poverty chain in the Global South? Third World Quarterly 38 (8): 1710-1732.

Microinsurance Network. 2020. The landscape of microinsurance 2020. https://microinsurancenetwork. org/the-landscape-of-microinsurance.

Tiemtore, A. 2021. Examining the effects of agricultural income insurance on farmers in Burkina Faso. Geneva Papers on Risk and Insurance: Issues and Practice. https://doi.org/10.1057/ s41288-021-00212-y.

Yan, Y., and Faure, M. 2021. Government interventions in microinsurance: evidence from China. Geneva Papers on Risk and Insurance: Issues and Practice. https://doi.org/10.1057/s41288-020-00202-6.

Zhang, X., Chen, Y., and Yao, Y. 2021. Dynamic information asymmetry in micro health insurance: implications for sustainability. Geneva Papers on Risk and Insurance: Issues and Practice. https:// doi.org/10.1057/s41288-020-00200-8.

Publisher's Note Springer Nature remains neutral with regard to jurisdictional claims in published maps and institutional affiliations. 


\section{About the authors}

David Mark Dror holds a Ph.D. in Economics and Management from Université Claude Bernard Lyon 1, France (Summa cum Laude), and a Doctorate in Business Administration in International Health Services (Magna cum Laude). David worked for the ILO as a senior specialist (health) at the Social Protection Sector. He held an appointment as an Honorary Professor at the Erasmus School of Health Policy and Management (Erasmus University Rotterdam). David established the Micro Insurance Academy (MIA) in New Delhi in 2007 and acted as its Chairman for a decade. During those years, the MIA became a prominent technical assistance provider to NGOs and grassroots groups that launched and operated communitybased health insurance and mutual-aid schemes for risks related to crops, livestock, human health and life risks. David was among the individuals that created the CGAP Working Group on microinsurance (which later became the MicroInsurance Network). David has published several books on health financing, microinsurance and risk modelling (published by the ILO, the World Bank, World Scientific Publishing and others) and about 100 peer-reviewed articles. His publications are among the most used in the microinsurance space.

Martin Eling is Professor of Insurance Management and Director of the Institute of Insurance Economics at the University of St. Gallen, Switzerland. He received his doctorate from the University of Münster, Germany and his habilitation from the University of St. Gallen. In 2008 he was Visiting Professor at the University of Wisconsin-Madison. From 2009 to 2011, he was Professor for Insurance at the University of Ulm, Germany. He does empirical research at the intersection of insurance business, mathematics and economics. Currently, the main research interests are cyber risk, social security and microinsurance. 